Title: Prioritizing Pregnant Women for COVID-19 Vaccination

Authors: Yamini Sarwal, MBBS. MD, MPH (Johns Hopkins) ${ }^{1}$

Tanvi Sarwal, MBBS ${ }^{2}$

Rakesh Sarwal,MBBS,MPH, DrPH (Johns Hopkins) ${ }^{3}$

1: Chief Medical Officer, Department of Obstetrics and Gynaecology, Vardhman Mahavir Medical College \& Safdarjung Hospital, New Delhi, India. Pin: 110023. (ysarwal@gmail.com)

2: Independent Researcher, New Delhi, India

Flat No. 601, Sanskriti Apartments, Sector 46, Faridabad, Haryana, India. Pin: 121010. (tanvi.20007@gmail.com)

3: Additional Secretary, NITI (National Institution for Transforming India), Parliament Street, New Delhi, India. Pin: 110001. (sarwalr@gmail.com)

Corresponding author (ysarwal@gmail.com)

OSF DOI: $10.31219 /$ osf.io/5yxh7 


\title{
Prioritizing Pregnant Women for COVID-19 Vaccination
}

\begin{abstract}
Even though evidence for safety and efficacy is emerging, most countries do not offer vaccination to pregnant women, despite they being at higher risk of complications from COVID-19. We did a web search on policies for COVID-19 vaccination of pregnant women in two sets of countries - those bearing a high burden of COVID-19 cases, and a second set with a high burden of maternal and under five mortality globally. Of the top 20 COVID-19 affected countries, nine allow vaccination of pregnant women, of which two preferentially vaccinate pregnant women. In contrast, four of the 20 high under-five mortality countries allow vaccination of pregnant women, while none has included them in the preferential group. India and Indonesia with one fifth of world's population fall in both the groups, but do not include pregnant women for COVID-19 vaccination. For COVID-19 not to further aggravate the already heavy burden of maternal and under five mortality, there is a strong case for inclusion of pregnant women as a high priority group for COVID-19 vaccination. We recommend including COVID-19 vaccination in the routine protocol for antenatal care in all countries, particularly India and Indonesia in view of their high dual burden.
\end{abstract}

Keywords: Pregnancy, COVID-19, Vaccination, under-five mortality, maternal mortality, dual burden of disease.

What is known:

- Vaccination against COVID-19 is known to protect against infection, and lower mortality

- Vaccination against COVID-19 is known to generate antibodies in pregnant women which are also found in cord blood and breastmilk

- Globally, 300,000 women died from pregnancy-related causes and 5.3 million under-fives dying before their fifth birthday.

What is not known:

- Overlap between countries facing high burden of COVID-19 cases, and those with a high burden of maternal and under five child mortality

- Policies on administration of COVID-19 vaccine for pregnant women across countries of the world 


\section{Introduction}

COVID-19 pandemic came on the top of high burden of under-five mortality in parts of the world, with 5.3 million under-fives dying before their fifth birthday, half of which occurred within first 28 days of life. This comes as a pushback to Sustainable Development Goal 3.2 which aims to achieve by 2030 an end to preventable deaths of newborns and children under-five, which appeared unreachable even without the pandemic. Similarly, 300,000 women died from pregnancy-related causes in $2015,{ }^{1}$ while achievement of Sustainable Development Goal 3.1 of 70 maternal deaths per 100,000 live births was appearing far unlikely at the start of pandemic.

Pregnancy is a time of increased demands on the body, lowered immune response, reduced ability to cope and increasing risk of complications from infections. Pregnant women are known to be at significantly higher risk for severe COVID-19 related complications compared with non-pregnant women. Hence, the issue of protecting pregnant women against COVID-19 is critical. Vaccination has emerged as a reliable protective measure against severe COVID-19 infection. ${ }^{2}{ }^{3}$ Currently, either pregnant women are not included for COVID-19 vaccination, or the policies are ambiguous with the decision being often left to the woman. Evidence is emerging of the safety and efficacy of COVID-19 vaccination, which along with benefits of passing on the protection to the newborn, call for including pregnant women in the high priority group for COVID-19 vaccination. In this paper, we list countries bearing high burden of COVID-19 cases, and compile their policies on vaccination during pregnancy. We do a similar exercise for countries with a high unfinished burden of maternal and under-five mortality. Lastly, we identify countries common to the two lists. We present our findings along with an argument for priority vaccination of pregnant women.

\section{Methods}

We accessed publicly available data on total COVID-19 cases, total COVID-19 deaths, vaccination rates, burden of maternal and under-five mortality from "Our World in Data" (https://ourworldindata.org/). We sorted countries by burden of COVID-19 cases, and under-five deaths. We also searched the web for policy on vaccination during pregnancy in high burden countries. We present our results in two tables listing total COVID-19 cases, maternal and under-five deaths with level of vaccination and policy environment.

\section{Results}

Top 20 countries by total COVID-19 cases (Table-1) carry a disproportionately large burden of cases (79\%) and COVID-19 deaths (81\%) globally. These set of countries also harbor $19 \%$ of all maternal deaths, and $24 \%$ of under-five deaths. Most of these countries have achieved a reasonable level of vaccination against COVID-19 with an average of $13 \%$, with USA topping the list with $40 \%$. Of the top 20 COVID19 affected countries, two countries (USA and UK) have in place guidelines for 
preferential vaccination of pregnant women and seven others (Brazil, France, Italy, Argentina, Spain, Mexico and Netherlands) allow COVID-19 vaccination for pregnant women.

Top 20 countries with the highest burden of under-five mortality (Table-2) account for $74 \%$ of all under-five deaths and also a similar proportion of global maternal deaths. These set of countries house 19\% of all COVID-19 cases, and $12 \%$ of COVID-19 deaths globally. Most of these countries have very low levels of vaccination against COVID-19 (average: $0.88 \%$ ), with a maximum of $3.7 \%$ in Indonesia and $3 \%$ in India. None of the high maternal and under-five mortality burden countries has preferential vaccination guidelines for pregnant women in place, while only four (Nigeria, China, Uganda and Somalia) allow vaccination of pregnant women.

Two countries - India and Indonesia - with one fifth of world's population lie in both the groups, contribute to $17 \%$ of COVID-19 cases, $11 \%$ of COVID-19 deaths, $17 \%$ of maternal and $21 \%$ of under five deaths globally. Neither country has yet allowed COVID-19 vaccination of pregnant women, thereby accentuating the already high risk to survival of mothers and under-five children. Anecdotal reports suggest that more pregnant women are dying from COVID-19 during the present wave of the pandemic in India than the earlier wave. ${ }^{4}$

\section{Why Prioritize Pregnant Women for COVID-19 Vaccination ?}

The arguments for vaccination of pregnant women against COVID-19 run as follows:

1. Pregnant women experience more severe COVID-19 disease than nonpregnant women. They are more likely to require hospitalization ${ }^{5}$, admission to Intensive Care Unit, receive invasive ventilation and extracorporeal membrane oxygenation when compared with non-pregnant women. There is a $70 \%$ increased risk of death among symptomatic pregnant women as compared to non-pregnant ones ${ }^{6}$. Physiological changes of pregnancy which include increased heart rate and oxygen consumption, oedema of the respiratory tract, decreased lung capacity, ${ }^{6}$ increased chances of thrombo-embolic disease and altered immune functions place pregnant women at a higher risk of all viral infections, including COVID-19. ${ }^{7}$ Women who get COVID-19 infection while pregnant, experience a higher maternal and neonatal morbidity \& mortality. These include higher incidence of pregnancy induced hypertension, pre-eclampsia, eclampsia, infections requiring antibiotics, more frequent referrals to higher centers, higher cesarean section rates, more chances of admission to Intensive Care Unit (ICU), High Dependency Unit (HDU) and longer hospital stay. Maternal mortality is more in the COVID-19 infected group compared to non-infected pregnant women. Preterm births, NICU stay for seven days or longer and neonatal death before discharge from hospital are all higher in COVID positive pregnancy group. ${ }^{8} 9$ Thus, there is a compelling need to protect 
pregnant women against COVID-19.

2. As regards the safety of vaccine against COVID-19, there have been no pre-authorised clinical trials involving pregnant women so far, since they were consciously excluded for ethical reasons. However, there are reasons to believe that COVID-19 vaccines are safe in pregnancy. Among the numerous pregnant women who have received COVID-19 vaccine globally, there have been no reports suggestive of concern so far; none of the vaccines contains live virus and hence it is extremely unlikely that a vaccine virus could replicate and cross the placenta and infect the foetus. Studies done on pregnant laboratory animals in DART studies (Developmental \& Reproductive Toxicity) have not provided any concerning results for Pfizer-BioNtech, Moderna, Johnson \& Johnson/Janssen, and Oxford-AstraZeneca vaccines. ${ }^{10}$ A study on 3958 pregnant women who received mRNA COVID-19 vaccine did not show obvious safety signals. Adverse pregnancy and neonatal outcomes among women who received MRNA COVID-19 vaccination were similar with those reported in other studies involving pregnant women before the pandemic. ${ }^{11}$ The mRNA vaccines seem to be safe for pregnant women, based on currently available data. Adenovirus vaccine ( Johnson \& Johnson/Janssen ${ }^{12}$ and Oxford-AstraZeneca (now called Vaxzevria) ${ }^{13}$ have been found to be associated with serious clotting disorder, Thrombosis with Thrombocytopenia Syndrome (TTS), in recipients under 50 year of age. This adverse effect, however, is very rare - four to seven events per million vaccination doses have been observed in different countries. Compared to enormous protection that the vaccine offers against COVID-19, this risk is very small, and therefore, vaccination of pregnant women is being recommended. ${ }^{14}$ However, where mRNA vaccines are available, as in USA and UK ${ }^{15}{ }^{16}$, women are being given the option to choose such a vaccine. The Australian government has also recommended pregnant women to preferably take the Pfizer COVID-19 vaccine. ${ }^{17}$

3. COVID-19 vaccines are as effective in pregnant women, as the general population. It has been shown that pregnant women elicit a robust humoral immune response after vaccination with immunogenicity and reactogenicity which is equivalent to that in non-pregnant women. Vaccine induced immune response is higher than that elicited in response to natural COVID-19. ${ }^{18}$ In order to break the cycle of virus transmission, mass scale immunization is necessary in a region, which would eventually make the region disease free. Most epidemiologists believe that a threshold of $70 \%$ protection by vaccination or infection would provide herd immunity in a population. ${ }^{19}$ This happened in Israel, where life has returned to near normal after $58 \%$ of its population got vaccinated. ${ }^{20}$ Wide immunization coverage in Israel included vaccination of pregnant women. ${ }^{21}$ COVID-19 infection after vaccination is known, but the viral load in such cases is substantially lower, as well as onward transmission of the virus. ${ }^{22} 23$

4. COVID-19 vaccination in pregnancy has dual benefit - both the mother and new-born get antibodies, which have been demonstrated in cord 
blood and breast milk. ${ }^{18}$ High IgA levels in early milk compared to later milk make a case for vaccination during pregnancy rather than in lactation. ${ }^{24}$ As of now, under-five children are not offered COVID-19 vaccine, but young people are becoming increasingly susceptible with newer variants, for example the P.1 variant in Brazil. 2526 Israel has placed pregnant women on high priority list for COVID-19 vaccination 2728 backed by studies in the country which show efficient materno-fetal, transplacental transfer of anti COVID-19 spike antibodies. ${ }^{29}$ China has also issued guidelines to include pregnant women as eligible for COVID19 vaccine, reversing an earlier decision. ${ }^{30}$

5. In view of higher risk of severe COVID-19 in pregnant women, WHO recommends that pregnant women with a history of underlying medical conditions may be vaccinated during pregnancy, after consulting their health care provider. ${ }^{10}$ Since pregnancy is a factor that leads to increase risk of COVID-19, CDC and American College of Obstetrics and Gynecologists (ACOG) have recommended including pregnant women as eligible to receive COVID-19 vaccine. Pregnant women are advised to discuss with their health care provider and make an informed decision regarding vaccination. ${ }^{14}$ In United Kingdom, Joint Committee on Vaccination \& Immunization (JCVI) has recommended that COVID-19 vaccines should be offered to pregnant women at the same time as the rest of the population, based on their age and clinical risk group. ${ }^{31}$ The Society for Maternal-Fetal-Medicine also supports COVID-19 vaccination in pregnancy when the benefits outweigh the risks. ${ }^{32}$ The European Medicines Agency also recommends that vaccination in pregnant women may be considered on a case-by-case basis. ${ }^{33}$ India's association of Obstetricians FOGSI ${ }^{34}$ and the National Technical Advisory Group (NTAGI) have recommended that pregnant women may be offered a choice to take any COVID-19 vaccine. ${ }^{35}$

6. Some parts of the world have a high burden of COVID-19 infection related morbidity and mortality and also moderate coverage of vaccination against the disease (Table-1). There are other countries with a high maternal and neonatal mortality (Table-2), that have worsened during the pandemic, both because of the added burden of the COVID-19 infection as well as due to lockdowns, hampering the utilization of health services. ${ }^{36}$ Two countries - India and Indonesia - fall in both the above categories where the impact of COVID-19 infection is high, maternal and under-five deaths are substantial and proportion of population vaccinated against COVID-19 is also low. This last category is hardest hit by the pandemic and is in urgent need for vaccination, including that of pregnant women as a high priority group. The challenge is to gear up immunization of pregnant women against the virus as well as improve utilization of antenatal services, while the social constraints and risk of infection posed by the pandemic continue to persist. 


\section{Discussion}

Woman bear multiple social responsibilities, particularly for the care of the children in the family, including breastfeeding. COVID-19 infection in pregnant woman places them at a higher risk both in terms of severity of infection as well as the course and outcome of pregnancy. There is also a lingering fear that she may pass on the virus to the baby while she is pregnant or after birth during breastfeeding or taking care of the newborn. It also paralyzes family dynamics, as self-isolation becomes difficult.

If a breastfeeding mother contracts COVID-19 infection, it poses a dilemma to whether keep the baby close-by and continue breastfeeding or isolate herself. This is despite WHO recommendation ${ }^{37}$ that rooming-in of baby with infected mother and breastfeeding should be continued with COVID-19 appropriate precautions, due to established role of breast milk in child development and survival. If vaccine is administered during pregnancy, the mother would have sufficient antibodies in breastmilk to protect the baby. For all the above reasons it is of utmost importance that pregnant women are immunized during pregnancy. Even though, COVID-19 vaccination is recommended for all lactating women in India ${ }^{38}$ pregnant women are still excluded.

An efficient way to achieve vaccination of pregnant women against COVID-19 is to include it in the routine antenatal care just like tetanus immunization and Ironfolic acid supplementation. ANC registration has fallen due to COVID-19 fear \& lock downs. ${ }^{39}$ Converging ANC with Covid-19 vaccination will maximize the coverage, with obvious positive influence on maternal and child outcomes. The setback due to COVID-19 on maternal-under-five health can be offset, and the pandemic used as an opportunity to further under-five survival revolution across the globe. To strike the right balance between optimal ANC care and restricting movements out of home, at least four face to face antenatal contacts have been recommended during the pandemic. ${ }^{40}$ Integrating COVID-19 vaccination into ANC protocol would reduce two extra visits for the former and naturally improve compliance to both. Timing of vaccination should be such that it elicits maximum antibody response in cord blood and colostrum / early milk, and its administration does not interfere with immune response to routine vaccination in pregnancy. Both these areas however warrant further research.

The adverse effect of thrombosis reported with Adenovirus vaccine, such as Oxford-AstraZeneca which is being administered by a majority of countries around the world ${ }^{41}$, has raised concerns about its safety, more so during pregnancy, which is a hypercoagulable state. In several countries mRNA vaccines are not available, and require stringent cold chain conditions with sub-zero temperature. For example, neither Indonesia (Astra Zenecea and Sinovac) nor India (Astra Zenecea, called Covishield and Covaxin) have mRNA vaccines. Sinovac and Covaxin are both killed vaccines, and even with the limited data available, are assumed to be safe in pregnancy. In view of the obvious benefits of vaccination, rare nature of the adverse event and to contain the COVID-19 pandemic, all countries, in particular India and Indonesia should use available vaccines for protecting pregnant women on priority. Like all recipients, pregnant women should 
have access to information about the safety and efficacy of the vaccine, including information about data that is not available.

\section{Conclusion}

Despite evidence of the safety and efficacy of COVID-19 vaccines, and the need for protecting pregnant women, only a few countries even in the face of a high burden of COVID-19 cases, maternal and under-five mortality have prioritized this group for vaccination. Countries like India and Indonesia facing a high burden of COVID-19 cases, and already existing burden of maternal and under-five mortality should particularly vaccinate pregnant women for the protection that it brings to the mother, and through transmission of antibodies in breast milk to the baby. The authors recommend that all countries should not only allow COVID-19 vaccination of pregnant women, but also prioritize this group. A systemic way of achieving high coverage of pregnant women would be to include COVID-19 vaccination in the protocol for antenatal care (with an opt out option). Thus, pregnant women should be treated as a high priority group. Immediate action is required to vaccinate pregnant women before the next wave of COVID-19 so that children born are protected, since they are likely to be more vulnerable to newer variants of this virus. If this strategy is adopted, the push-back due to COVID-19 pandemic can be converted into an opportunity to increase coverage of routine antenatal care services, while protecting mothers and their to be born babies against COVID-19 infections. 


\section{Declarations}

\section{Availability of data and materials}

All the data supporting the results reported in the article can be found freely online, mainly at https://ourworldindata.org/

\section{Competing interests}

The authors declare that they have no competing interests.

\section{Funding}

No funding has been received from any source for this work.

\section{Authors' contributions}

YS conceptualized the study, compiled information from web sources, wrote the paper. TS performed the literature review, and was a major contributor in writing the manuscript. RS tabulated the data and interpreted the data. All authors read and approved the final manuscript.

\section{Acknowledgements}

Johns Hopkins University for placing data on COVID-19, Maternal and under-five mortality on one, inter-operable platform. 
References

1.Roser M and Ritchie H: Maternal Mortality. Our World in Data. 2013. Available from:

https://ourworldindata.org/maternal-mortality

2.Haas EJ, Angulo FJ, McLaughlin JM, Anis E, Singer SR, Khan F, Brooks N, Smaja M, Mircus G, Pan K, Southern J, Swerdlow DL, Jodar L, Levy Y and Alroy-Preis S: Impact and effectiveness of mRNA BNT162b2 vaccine against SARS-CoV-2 infections and COVID-19 cases, hospitalisations, and deaths following a nationwide vaccination campaign in Israel: an observational study using national surveillance data. The Lancet. 2021;397:1819-1829.

Available from: http://dx.doi.org/10.1016/S0140-6736(21)00947-8 DOI: 10.1016/s01406736(21)00947-8

3.Angel Y, Spitzer A, Henig O, Saiag E, Sprecher E, Padova H and Ben-Ami R: Association Between Vaccination With BNT162b2 and Incidence of Symptomatic and Asymptomatic SARSCoV-2 Infections Among Health Care Workers. \{JAMA\}. 2021. DOI: 10.1001/jama.2021.7152 4.Allana A: Why Is the Virus Killing So Many Pregnant Women in India?. 2021. Available from: https://www.nytimes.com/2021/05/23/opinion/india-covid-pregnant-women.html

5.Ellington S, Strid P, Tong VT, Woodworth K, Galang RR, Zambrano LD, Nahabedian J, Anderson K and Gilboa SM: Characteristics of Women of Reproductive Age with LaboratoryConfirmed SARS-CoV-2 Infection by Pregnancy Status - United States, January 22-June 7, 2020. \{MMWR\}. Morbidity and Mortality Weekly Report. 2020;69:769-775. DOI:

10.15585/mmwr.mm6925a1

6.Zambrano LD, Ellington S, Strid P, Galang RR, Oduyebo T, Tong VT, Woodworth KR, Nahabedian JF, Azziz-Baumgartner E, Gilboa SM, Meaney-Delman D, Akosa A, Bennett C, Burkel V, Chang D, Delaney A, Fox C, Griffin I, Hsia J, Krause K, Lewis E, Manning S, Mohamoud Y, Newton S, Olsen EO, Perez M, Reynolds M, Riser A, Rivera M, Roth NM, Sancken C, Shinde N, Smoots A, Snead M, Wallace B, Whitehill F, Whitehouse E and Zapata L: Update: Characteristics of Symptomatic Women of Reproductive Age with LaboratoryConfirmed SARS-CoV-2 Infection by Pregnancy Status - United States, January 22-October 3, 2020. MMWR. Morbidity and Mortality Weekly Report. 2020;69. Available from: http://dx.doi.org/10.15585/mmwr.mm6944e3 DOI: 10.15585/mmwr.mm6944e3 7.Koumoutsea EV, Vivanti AJ, Shehata N, Benachi A, Gouez AL, Desconclois C, Whittle W, Snelgrove $\mathrm{J}$ and Malinowski AK: COVID-19 and acute coagulopathy in pregnancy. Journal of Thrombosis and Haemostasis. 2020;18:1648-1652. DOI: 10.1111/jth.14856

8.Villar J, Ariff S, Gunier RB, Thiruvengadam R, Rauch S, Kholin A, Roggero P, Prefumo F, do Vale MS, Cardona-Perez JA, Maiz N, Cetin I, Savasi V, Deruelle P, Easter SR, Sichitiu J, Conti CPS, Ernawati E, Mhatre M, Teji JS, Liu B, Capelli C, Oberto M, Salazar L, Gravett MG, Cavoretto PI, Nachinab VB, Galadanci H, Oros D, Ayede AI, Sentilhes L, Bako B, Savorani M, Cena H, Garca-May PK, Etuk S, Casale R, Abd-Elsalam S, Ikenoue S, Aminu MB, Vecciarelli C, Duro EA, Usman MA, John-Akinola Y, Nieto R, Ferrazi E, Bhutta ZA, Langer A, Kennedy SH and Papageorghiou AT: Maternal and Neonatal Morbidity and Mortality Among Pregnant Women With and Without COVID-19 Infection. JAMA Pediatrics. 2021. Available from: http://dx.doi.org/10.1001/jamapediatrics.2021.1050 DOI: 10.1001/jamapediatrics.2021.1050 9.Allotey J, Stallings E, Bonet M, Yap M, Chatterjee S, Kew T, Debenham L, Llavall AC, Dixit A, Zhou D, Balaji R, Lee SI, Qiu X, Yuan M, Coomar D, Sheikh J, Lawson H, Ansari K, van Wely M, van Leeuwen E, Kostova E, Kunst H, Khalil A, Tiberi S, Brizuela V, Broutet N, Kara E, Kim CR, Thorson A, Escuriet R, Oladapo OT, Mofenson L, Zamora J and Thangaratinam S: Clinical manifestations, risk factors, and maternal and perinatal outcomes of coronavirus disease 2019 in pregnancy: living systematic review and meta-analysis. \{BMJ\}. 2020:m3320. DOI:

10.1136/bmj.m3320

10.WHO: Safety of COVID-19 Vaccines. 2021. Available from:

https://www.who.int/news-room/feature-stories/detail/safety-of-covid-19-vaccines 
11.Shimabukuro TT, Kim SY, Myers TR, Moro PL, Oduyebo T, Panagiotakopoulos L, Marquez PL, Olson CK, Liu R, Chang KT, Ellington SR, Burkel VK, Smoots AN, Green CJ, Licata C, Zhang BC, Alimchandani M, Mba-Jonas A, Martin SW, Gee JM and Meaney-Delman DM: Preliminary Findings of mRNA Covid-19 Vaccine Safety in Pregnant Persons. New England Journal of Medicine. 2021. Available from: http://dx.doi.org/10.1056/NEJMoa2104983 DOI: 10.1056/nejmoa2104983

12.See I, Su JR, Lale A, Woo EJ, Guh AY, Shimabukuro TT, Streiff MB, Rao AK, Wheeler AP, Beavers SF, Durbin AP, Edwards K, Miller E, Harrington TA, Mba-Jonas A, Nair N, Nguyen DT, Talaat KR, Urrutia VC, Walker SC, Creech CB, Clark TA, DeStefano F and Broder KR: US Case Reports of Cerebral Venous Sinus Thrombosis With Thrombocytopenia After Ad26.COV2.S Vaccination, March 2 to April 21, 2021. \{JAMA\}. 2021. DOI: 10.1001/jama.2021.7517 13.Schultz NH, Sørvoll IH, Michelsen AE, Munthe LA, Lund-Johansen F, Ahlen MT, Wiedmann M, Aamodt A-H, Skattør TH, Tjønnfjord GE and Holme PA: Thrombosis and Thrombocytopenia after ChAdOx1 nCoV-19 Vaccination. New England Journal of Medicine. 2021. DOI:

10.1056/nejmoa2104882

14.CDC: COVID-19 Vaccines While Pregnant or Breastfeeding. 2021. Available from: https://www.cdc.gov/coronavirus/2019-ncov/vaccines/recommendations/pregnancy.html 15.ACOG: Vaccinating Pregnant and Lactating Patients Against COVID-19. 2020. Available from: https://www.acog.org/clinical/clinical-guidance/practice-advisory/articles/2020/12/ vaccinating-pregnant-and-lactating-patients-against-covid-19 16. Reuters: Pregnant women in UK told to have Pfizer or Moderna vaccines. 2021. Available from: https://english.alarabiya.net/coronavirus/2021/04/16/Pregnant-women-in-UK-told-to-havePfizer-or-Moderna-vaccines-

17.Health AGDo: About the AstraZeneca COVID-19 vaccine. Australian Government Department of Health. 2021. Available from: https://www.health.gov.au/initiatives-andprograms/covid-19-vaccines/learn-about-covid-19-vaccines/about-the-astrazeneca-covid-19vaccine 18.Gray KJ, Bordt EA, Atyeo C, Deriso E, Akinwunmi B, Young N, Baez AM, Shook LL, Cvrk D, James K, Guzman RD, Brigida S, Diouf K, Goldfarb I, Bebell LM, Yonker LM, Fasano A, Rabi SA, Elovitz MA, Alter G and Edlow AG: Coronavirus disease 2019 vaccine response in pregnant and lactating women: a cohort study. American Journal of Obstetrics and Gynecology. 2021. Available from: http://dx.doi.org/10.1016/j.ajog.2021.03.023 DOI: 10.1016/j.ajog.2021.03.023 19.Leshem $E$ and Lopman BA: Population immunity and vaccine protection against infection. The Lancet. 2021;397:1685-1687. DOI: 10.1016/s0140-6736(21)00870-9 20.IndiaToday: 'Unmasking' Israel: How rapid vaccination against Covid is returning lives to normal here. 2021. Available from: https://www.indiatoday.in/diu/story/-unmasking-israel-howrapid-vaccination-against-covid-is-returning-lives-to-normal-here-1795188-2021-04-26 21.Berger M: Israel recommends coronavirus vaccine for pregnant women, marking a shift as some countries reassess risk. 2021. Available from: https://www.washingtonpost.com/world/2021/01/22/coronavirus-vaccine-pregnant-womenisrael-risks/ 22.CDC: Science Brief: COVID-19 Vaccines and Vaccination: Summary of Recent Changes. 2021. Available from: https://www.cdc.gov/coronavirus/2019-ncov/science/science-briefs/fullyvaccinated-people.html

23.Levine-Tiefenbrun M, Yelin I, Katz R, Herzel E, Golan Z, Schreiber L, Wolf T, Nadler V, BenTov A, Kuint J, Gazit S, Patalon T, Chodick G and Kishony R: Initial report of decreased SARSCoV-2 viral load after inoculation with the BNT162b2 vaccine. Nature Medicine. 2021;27:790792. DOI: $10.1038 / \mathrm{s} 41591-021-01316-7$

24.Collier A-rY, McMahan K, Yu J, Tostanoski LH, Aguayo R, Ansel J, Chandrashekar A, Patel S, Bondzie EA, Sellers D, Barrett J, Sanborn O, Wan H, Chang A, Anioke T, Nkolola J, Bradshaw C, Jacob-Dolan C, Feldman J, Gebre M, Borducchi EN, Liu J, Schmidt AG, 
Suscovich T, Linde C, Alter G, Hacker MR and Barouch DH: Immunogenicity of COVID-19 mRNA Vaccines in Pregnant and Lactating Women. JAMA. 2021. Available from: http://dx.doi.org/10.1001/jama.2021.7563 DOI: 10.1001/jama.2021.7563

25.NYT: In Brazil, babies and small children are dying of the virus in disturbingly high numbers. 2021. Available from: https://www.nytimes.com/live/2021/05/16/world/covid-vaccinecoronavirus-cases?name=styln-vaccines-

combo\&region=TOP_BANNER\&block=storyline_menu_recirc\&action=click\&pgtype=Interactive \&variant=1_Show\&is_new=false\#in-brazil-babies-and-small-children-are-dying-of-the-virus-indisturbingly-high-numbers

26. Taylor L: Covid-19: Brazil's spiralling crisis is increasingly affecting young people. \{BMJ\}. 2021:n879. DOI: 10.1136/bmj.n879

27.: Israel includes pregnant women on Covid-19 vaccines priority list. 2021. Available from: https://health.economictimes.indiatimes.com/news/policy/israel-includes-pregnant-women-oncovid-19-vaccines-priority-list/80377668

28.Gov.il: Vaccinating Women who are Planning a Pregnancy, Pregnant or Breastfeeding with the COVID-19 Vaccine - Clarification. GOV.IL. 2021. Available from:

https://www.gov.il/en/departments/news/28012021-03

29.Rottenstreich A, Zarbiv G, Oiknine-Djian E, Zigron R, Wolf DG and Porat S: Efficient maternofetal transplacental transfer of anti- SARS-CoV-2 spike antibodies after antenatal SARS-CoV-2 BNT162b2 mRNA vaccination. 2021. DOI: 10.1101/2021.03.11.21253352 30.Chaoyan Z: Pregnant Women Can Get Vaccinated for COVID-19, China Clarifies. 2021. Available from: https://www.sixthtone.com/news/1007105/pregnant-women-can-get-vaccinatedfor-covid-19,-china-clarifies

31.RCOG: COVID-19 vaccines, pregnancy and breastfeeding. 2021. Available from:

https://www.rcog.org.uk/en/guidelines-research-services/coronavirus-covid-19-pregnancy-andwomens-health/covid-19-vaccines-and-pregnancy/covid-19-vaccines-pregnancy-andbreastfeeding/

32.SocietyForMaternalFoetalMEdicine: Experts in High-Risk Pregnancy Respond to the FDA's Decision to Offer the Newly Approved COVID-19 Vaccine to Pregnant and Lactating People. 2020. Available from: https://s3.amazonaws.com/cdn.smfm.org/media/2632/FDA_final.pdf 33.SuperiorHealthCouncil: Recommendations for vaccinating pregnant women, women wishing to conceive and breastfeeding mothers against SARS-COV-2 using an mRNA vaccine. 2020. Available from: https://www.nitag-resource.org/sites/default/files/2021-

02/20210126_shc_9622_covid-19_vaccination_pregnant_woman_breastfeeding_vweb.pdf 34.FOGSI: FOGSI Position Statement Covid Vaccination For Pregnant \& Breastfeeding Women. 2021. Available from: https://www.fogsi.org/wp-content/uploads/covid19/fogsistatement-on-covid-vaccination-in-pregnancy-and-bf.pdf 35.Singh S: Pregnant Women Can Choose COVID Vaccine; Lactating Mothers Eligible For Jabs: Govt Panel. 2021. Available from: https://www.republicworld.com/india-news/generalnews/pregnant-women-can-choose-covid-vaccine-lactating-mothers-eligible-for-jabs-govtpanel.html

36.Rahman MA, Halder HR and Islam SMS: Effects of COVID-19 on maternal institutional delivery: Fear of a rise in maternal mortality. Journal of Global Health. 2021;11. DOI:

10.7189/jogh.11.03041

37.WHO: Breastfeeding and COVID-19 Scientific Brief. 2020. Available from: https://www.who.int/news-room/commentaries/detail/breastfeeding-and-covid-19 38.MoHFW: New Recommendations of NEGVAC accepted by Union Ministry of Health. 2021. Available from: https://pib.gov.in/PressReleasePage.aspx?PRID=1719925 39.Goyal M, Singh P, Singh K, Shekhar S, Agrawal N and Misra S: The effect of the COVID-19 pandemic on maternal health due to delay in seeking health care: Experience from a tertiary 
center. International Journal of Gynecology $\{\backslash \&\}$ Obstetrics. 2020;152:231-235. DOI: 10.1002/ijgo.13457

40.UNFPA: COVID-19 Technical BriefPackagefor Maternity Services. 2020. Available from: https://www.unfpa.org/sites/default/files/resource-pdf/COVID-

19_Maternity_Services_TB_Package_UPDATE_2_14072020_SBZ.pdf

41.OurWorldinData: Coronavirus (COVID-19) Vaccinations - Statistics and Research. Our World in Data. 2021. Available from: https://ourworldindata.org/covid-vaccinations 


\section{Table-1: Status of Policies on Vaccination in Pregnancy in 20 High Burden COVID-19 Countries}

\begin{tabular}{|c|c|c|c|c|c|c|}
\hline Country & Covid cases & Covid deaths & Vaccinated & $\begin{array}{l}\text { Maternal } \\
\text { deaths per } \\
\text { year }\end{array}$ & $\begin{array}{l}\text { Under Five } \\
\text { deaths per } \\
\text { year }\end{array}$ & $\begin{array}{l}\text { Pregnant women } \\
\text { included for } \\
\text { COVID-19 } \\
\text { vaccination }\end{array}$ \\
\hline United States & $33,217,995$ & 593,288 & 39.7 & 550 & 26,867 & Yes, on priority \\
\hline India & $27,555,457$ & 318,895 & 3.07 & 45,000 & 989,167 & No \\
\hline Brazil & $16,342,162$ & 456,674 & 10.13 & 1,300 & 43,278 & Yes \\
\hline France & $5,697,076$ & 109,327 & 15.3 & 66 & 3,235 & Yes \\
\hline Turkey & $5,220,549$ & 46,970 & 14.5 & 210 & 14,979 & No \\
\hline Russia & $4,977,332$ & 117,990 & 7.89 & 450 & 13,777 & No \\
\hline United Kingdom & $4,489,552$ & 128,020 & 35.42 & 74 & 3,487 & Yes, on priority \\
\hline Italy & $4,205,970$ & 125,793 & 18.53 & 18 & 1,646 & Yes \\
\hline Germany & $3,673,990$ & 88,192 & 16.32 & 42 & 2,687 & No \\
\hline Argentina & $3,663,215$ & 76,135 & 5.57 & 390 & 7,793 & Yes \\
\hline Spain & $3,663,176$ & 79,888 & 18.43 & 21 & 1,239 & Yes \\
\hline Colombia & $3,319,193$ & 86,693 & 6.28 & 480 & 10,841 & No \\
\hline Iran & $2,875,858$ & 79,384 & 0.48 & 340 & 19,562 & No \\
\hline Poland & $2,869,652$ & 73,440 & 16.67 & 12 & 1,679 & No \\
\hline Mexico & $2,405,772$ & 222,661 & 9.24 & 890 & 30,973 & Yes \\
\hline Ukraine & $2,251,242$ & 52,088 & 0.27 & 120 & 4,130 & No \\
\hline Peru & $1,942,054$ & 68,816 & 3.18 & 420 & 9,133 & No \\
\hline Indonesia & $1,797,499$ & 49,907 & 3.74 & 6,400 & 125,213 & No \\
\hline Netherlands & $1,664,708$ & 17,866 & 15.56 & 12 & 706 & Yes \\
\hline Czechia & $1,659,980$ & 30,059 & 12.75 & 5 & 358 & NA \\
\hline$\%$ of Global & $79 \%$ & $81 \%$ & & $19 \%$ & $24 \%$ & \\
\hline \multicolumn{7}{|c|}{ N: Covid (220); Maternal deaths (182); Under Five Deaths (192) } \\
\hline \multicolumn{7}{|c|}{ Covid cases : Total COVID-19 cases } \\
\hline \multicolumn{7}{|c|}{ Covid deaths: Total COVID-19 deaths } \\
\hline \multicolumn{7}{|c|}{ Vaccinated: Persons Fully vaccinated against COVID-19 per 100 population } \\
\hline \multicolumn{7}{|c|}{ Maternal deaths Total number of maternal deaths in one year } \\
\hline \multicolumn{7}{|c|}{ Under Five Deaths in Children under five years dying in one year } \\
\hline \multicolumn{7}{|c|}{ Data as on 29-05-20 accessed from https://ourworldindata.org/ } \\
\hline
\end{tabular}


Table-2: Status of Policies on COVID-19 Vaccination in Pregnancy in 20 Countries with High Maternal and under-five Mortality

\begin{tabular}{|c|c|c|c|c|c|c|}
\hline Country & Covid cases & Covid deaths & Vaccinated & $\begin{array}{l}\text { Maternal } \\
\text { deaths per } \\
\text { year }\end{array}$ & $\begin{array}{l}\text { Under Five } \\
\text { deaths per } \\
\text { year }\end{array}$ & \begin{tabular}{|l|} 
Pregnant \\
women \\
included for \\
COVID-19 \\
vaccination
\end{tabular} \\
\hline India & $27,555,457$ & 318,895 & 3.07 & 45,000 & 989,167 & No \\
\hline Nigeria & 166,191 & 2,071 & 0 & 58,000 & 714,188 & Yes \\
\hline Pakistan & 913,784 & 20,607 & 0.69 & 9,700 & 403,638 & No \\
\hline Democratic Republic of Congo & 31,279 & 781 & NA & 22,000 & 299,985 & No \\
\hline Ethiopia & 270,527 & 4,127 & NA & 11,000 & 188,690 & NA \\
\hline China & 91,096 & 4,636 & NA & 4,400 & 155,576 & Yes \\
\hline Indonesia & $1,797,499$ & 49,907 & 3.74 & 6,400 & 125,213 & NA \\
\hline Tanzania & 509 & 21 & NA & 8,200 & 113,824 & No \\
\hline Bangladesh & 794,985 & 12,480 & 2.48 & 5,500 & 99,608 & No \\
\hline Angola & 33,607 & 745 & 0.6 & 5,400 & 96,345 & NA \\
\hline Uganda & 44,594 & 361 & 0.01 & 5,700 & 84,968 & Yes \\
\hline Niger & 5,406 & 192 & 0.03 & 5,400 & 82,322 & NA \\
\hline Sudan & 34,889 & 2,600 & 0.2 & 4,100 & 81,825 & NA \\
\hline Mozambique & 70,673 & 834 & 0.24 & 5,300 & 80,562 & No \\
\hline Mali & 14,259 & 514 & 0.07 & 4,400 & 80,332 & NA \\
\hline Somalia & 14,647 & 768 & NA & 3,400 & 77,644 & Yes \\
\hline Afghanistan & 68,366 & 2,869 & 0.29 & 4,300 & 77,300 & No \\
\hline Cote d'Ivoire & 47,146 & 301 & NA & 5,400 & 76,571 & NA \\
\hline Chad & 4,926 & 173 & NA & 5,400 & 75,761 & No \\
\hline Cameroon & 77,982 & 1,270 & 0.03 & 5,100 & 70,649 & NA \\
\hline$\%$ of Global & $19 \%$ & $12 \%$ & & $74 \%$ & $74 \%$ & \\
\hline \multicolumn{7}{|c|}{ N: Covid (220); Maternal deaths (182); Under Five Deaths (192) } \\
\hline \multicolumn{7}{|c|}{ Covid cases : Total COVID-19 cases } \\
\hline \multicolumn{7}{|c|}{ Covid deaths: Total COVID-19 deaths } \\
\hline \multicolumn{7}{|c|}{ Vaccinated: Persons Fully vaccinated against COVID-19 per 100 population } \\
\hline \multicolumn{7}{|c|}{ Maternal deaths Total number of maternal deaths in one year } \\
\hline \multicolumn{7}{|c|}{ Under Five Deaths in Children under five years dying in one year } \\
\hline \multicolumn{7}{|c|}{ Data as on 29-05-20 accessed from https://ourworldindata.org/ } \\
\hline NA: Data Not Available & & & & & & \\
\hline
\end{tabular}

